\title{
ISL NEWS
}

\section{ESL 2022 - CONGRESS OF EUROPEAN SOCIETY OF LYMPHOLOGY}

Domus Pacis • Santa Maria degli Angeli • Assisi • Italy

JUNE 16-18, 2022

https://www.eurolymphology.org/announcement-of-2022-esl-congress-with-pdf-brochure

\author{
Marina Cestari MD \\ Congress President \\ Francesco Boccardo \\ ESL President
}

\section{ORGANIZING SECRETARIAT}

G.C. Congressi

Via P. Borsieri,12 - 00195 Roma

Tel. 06-3729466

Fax 06-37352337

Tel. diretto 06-3729510

Cellulare 335-8228909

E-mail: andreina.mancini@gccongressi.it Website: www.gccongressi.it

Art. 6-ISL Constitution: Membership in the Society can be obtained on the basis of a written application. Names of new applicants will be published in the Society's Bulletin. Any member who objects to the admittance of a candidate must state their objections in writing to the Secretary-General no later than one (1) month after publication of the Bulletin. The reasons for the objection must be stated... 